\title{
Conservation introduction of the threatened Apennine chamois Rupicapra pyrenaica ornata: post-release dispersal differs between wild-caught and captive founders
}

\author{
A. Bocci, S. Menapace, S. Alemanno and S. Lovari
}

\begin{abstract}
Sixteen Apennine chamois Rupicapra pyrenaica ornata (10 females, 6 males) were released into a protected area, the Sibillini Mountains National Park, Central Apennines, Italy, and monitored using global positioning system radio tags during 2008-2010. Founders caught in the wild $(n=8)$ and those reared in large enclosures $(n=8)$ differed in movement frequency (inter-fix distance per hour) and maximum distance covered (from the release site) in the first 5 months after release: both were significantly greater in wild individuals, males moved significantly more than females, wild individuals shifted their home ranges significantly more often than captive ones, and no differences were observed between the sexes or age classes. A mixed strategy of selection of wild and captive founders has proven successful in preventing large movements in the initial stages of release yet still providing sufficient opportunity to avoid inbreeding depression.
\end{abstract}

Keywords Apennines, Italy, ranging behaviour, reintroduction, reproductive success, Rupicapra pyrenaica ornata, Sibillini Mountains National Park

\section{Introduction}

The success of reintroductions or introductions of the reintroduced/introduced populations) depends on several factors, such as the number of individuals released (Berger, 1990; Beck et al., 1994; Saltz, 1998; Wolf et al., 1998; Fischer \& Lindenmayer, 2000; Clark et al., 2002), their age and sex (Komers \& Curman, 2000; Apollonio et al., 2003), sanitary status (Cunningham, 1996; Mathews et al., 2006), origin (from the wild or from captive-breeding programmes; Fischer \& Lindenmayer, 2000; Sarrazin \& Legendre, 2000; Vickery \& Mason, 2003; Jule et al., 2008), number of releases (Saltz, 1998), habitat suitability (Wolf et al., 1998; Owen-Smith, 2003) and connectivity between

A. Bocci, S. Menapace, S. Alemanno and S. Lovari (Corresponding author) Department of Life Sciences, Research Unit of Behavioural Ecology, Ethology and Wildlife Management, University of Siena, via P.A. Mattioli 4, 53100 Siena, Italy. E-mail lovari@unisi.it

Received 26 May 2013. Revision requested 6 September 2013.

Accepted 13 January 2014. First published online zo July 2014. metapopulations (Wolf et al., 1998; Festa-Bianchet, 2002). Population persistence is more likely when the number of founders is large (Fischer \& Lindenmayer, 2000), the rate of population increase is high (Griffith et al., 1989) and the effect of competition is low (Burgman \& Lindenmayer, 1998).

Reintroduction programmes should incorporate feasibility studies and preparatory activities (e.g. removing causes of former extinction) as well as a monitoring period after release (IUCN, 2012). Reintroduction methods and post-release ranging behaviour may be assessed through monitoring, the latter depending on the response to the new environment (Stanley Price, 1989).

The use of previous results to design further operations is a central concept of adaptive management. The monitoring period that should follow reintroductions is often neglected or documented only in grey literature (Sarrazin \& Barbault, 1996), or the project duration is insufficient to complete the monitoring (Beck et al., 1994). In the case of the Apennine chamois Rupicapra pyrenaica ornata in Italy, apart from a short article (Lovari et al., 2010) there is no information available on its post-release behaviour or the factors that determine the success of conservation actions, despite the large number of introductions/reintroductions that have been attempted since the early 1990 os.

The selection and availability of individuals of appropriate age and sex are the main concerns in introductions/ reintroductions. Given the lack of information on the consequences of various release strategies, arbitrary approaches are used to select individuals for population restoration (Caughley, 1994; Sarrazin \& Barbault, 1996). Adults are usually preferred (Komers \& Curman, 2000; Sarrazin \& Legendre, 2000) because young individuals may suffer high post-release mortality (Gogan \& Barrett, 1987), and populations with mature animals grow faster (Komers \& Curman, 2000). In reintroductions of polygynous species the number of females is usually maximized to increase the production of offspring (Sigg et al., 2005). Adult females are preferred to subadult females because primiparous mammals are often less fecund than older ones and they are more susceptible to environmental stress, which could further decrease fecundity (Bronson, 1989). In ungulates young males are the dispersing individuals (Greenwood, 1980), to decrease the risk of inbreeding. Reintroduced individuals may come from captive-breeding programmes or be 
translocated from natural populations. Captive-bred individuals may suffer higher mortality compared to wildcaught individuals (Ginsberg, 1994) and display behavioural limitations when released into the wild, because of lack of familiarity with the local habitat and ecosystem (Curio, 1996). The availability of individuals for release may vary among species but wild-caught animals are often preferred (Bright \& Morris, 1994).

In the first months after release translocated animals may exhibit an altered ranging behaviour because they need to locate resources (Owen-Smith, 2003) and become familiar with the new environment (Michallet \& Toïgo, 2000; Dolev et al., 2002). Explorative movements can increase the risk of mortality (Banks et al., 2002), affecting the success of reintroduction.

The Apennine chamois is protected under national and international legislation (Appendix II of the Bern Convention, Annex II ${ }^{*}$ and Annex IV of the EU Habitats and Species Directive, Appendix II of CITES, and as an 'especially protected species' under Italian hunting law). It is categorized as Vulnerable (criterion $\mathrm{D}_{1+2}$ ) on the IUCN Red List, with four small populations in as many national parks.

In the Holocene the Apennine chamois ranged along the Apennines, from the Sibillini Mountains to the Pollino massif (Masini \& Lovari, 1988), but by the early 1990s the species survived only in the Abruzzo, Lazio and Molise National Park. In 2008 there were three extant populations of several hundred animals, following two reintroductions in the early 1990s (Mari \& Lovari, 2006), in Majella National Park and the Gran Sasso-Monti Laga National Park. Thus, the species was not present in our study area in historical times. A hard release (i.e. immediate release of animals to the wild, without previous confinement or acclimatization) was carried out in the Sibillini Mountains in 2008 as part of several conservation projects (Reintroduction Programme and LIFEo9 NAT/IT/ooo183 COORNATA) for this threatened species and was preceded by a feasibility study (WWF, 1997). A captive population $(n=18)$ was kept in large enclosures in four national parks in the Central Apennines.

We investigated the post-release phase of a conservation introduction of Apennine chamois to an area of the Central Apennines, focusing on the sex, age and origin (captive-bred or wild) of translocated individuals, to gather data to inform future releases.

\section{Study area}

Our study area covered 850 ha in the Mount Bove area of the Sibillini Mountains National Park (70,00o ha) in the Central Apennines, Italy (Fig. 1). At low altitudes, beech Fagus sylvatica (on the northern slopes), oak Quercus spp. and European hop hornbeam Ostrya carpinifolia (on the southern slopes) are dominant, and at higher elevations grasslands of Festuco-Trifolietum thalii alternate with rocky walls.

The climate is high-mountainous at 1,350-1,850 $\mathrm{m}$ (mean annual temperature $7-9{ }^{\circ} \mathrm{C}$; mean annual precipitation 1,300-1,500 mm) and sub-alpine at 1,850-2,300 m (mean annual temperature $<5-6{ }^{\circ} \mathrm{C}$; mean annual precipitation 1,300-1,500 mm).

Wild boar Sus scrofa (c. 1,700), roe deer Capreolus capreolus (c. 900), red deer Cervus elaphus (c. 90) and Canis lupus (c. 25-30) are present in the Park. Chamois kids are vulnerable to predation by golden eagles Aquila chrysaetos (four nesting pairs) and possibly the red fox Vulpes vulpes (Couturier, 1938; Bertolino, 2003).

\section{Methods}

During 2008-2010 16 Apennine chamois (10 females, 6 males; Table 1) were released into the Sibillini Mountains National Park, increasing the population there by $41 \%$, to 55. Eight of the animals (two females $<_{3}$ years old; three females $\geq 3$ years old; one male $<4$ years old; two males $\geq 4$ years old) were caught in the wild, in the core distribution area of the Apennine chamois (Abruzzo Lazio and Molise National Park; Fig. 1). The others were caught in three fenced wildlife areas in Majella National Park (4.2 ha; Fig. 1; one female $<_{3}$ years old; one female $\geq 3$ years old; one male $<4$ years old), Gran Sasso-Monti Laga National Park ( 4 ha; Fig. 1; one female $<3$ years old; one female $\geq_{3}$ years old; one male $<_{4}$ years old), and Sibillini Mountains National Park ( 3 ha; Fig. 1; one female $<3$ years old; one male $<_{4}$ years old). One to three animals were released at a time because of the low availability of founders. In each release group the animals were all wild or all captivebred. Capture and release occurred in late summer/early autumn, well before the reproductive season.

All individuals were fitted with global positioning systems (GPS) or VHF radio-collars and translocated by road or helicopter to the Sibillini Mountains National Park. Both types of collars were equipped with mortality sensors. The methods of capture and handling were in accordance with the legislation on animal care in Italy.

Our sampling regime involved 42 fixes per individual per month, evenly distributed over daylight hours, for chamois fitted with VHF transmitters. At least three bearings (loudest signal method; Springer, 1979) were used to locate chamois and there was a minimum time period of 4 hours between two consecutive fixes. GPS transmitters were programmed to record locations every 7 hours and to transmit data by GSM (global system for mobile communications).

Radio-tracking data were analysed using Animal Movement v. 2.o beta for ArcView v. 3.2 (Hooge \& Eichenlaub, 1997). In the first 20 weeks after release the spatial behaviour of chamois was analysed in terms of (1) hourly standardized 
TABLE 1 The origin and age of the 16 Apennine chamois Rupicapra pyrenaica ornata released in the Sibillini Mountains National Park, Italy (Fig. 1), during 2008-2010.

\begin{tabular}{|c|c|c|}
\hline $\mathrm{ID}^{1}$ & Origin & Age (years) \\
\hline$\overline{\text { F1 }}$ & Wild & 10.5 \\
\hline $\mathrm{F} 2^{2}$ & Wild & 2.5 \\
\hline $\mathrm{F}^{2}{ }^{2}$ & Wild & 4.5 \\
\hline $\mathrm{F} 4$ & Wild & 2.5 \\
\hline $\mathrm{F} 5^{2}$ & Wild & 5.5 \\
\hline $\mathrm{F} 6^{2}$ & Enclosure & 2.5 \\
\hline $\mathrm{F} 7^{2}$ & Enclosure & 11.5 \\
\hline $\mathrm{F} 8^{2}$ & Enclosure & 3.5 \\
\hline $\mathrm{F} 9^{2}$ & Enclosure & 4.5 \\
\hline F10 & Enclosure & 3.5 \\
\hline M1 & Wild & 4.5 \\
\hline M2 & Wild & 2.5 \\
\hline $\mathrm{M}^{3}$ & Wild & 7.5 \\
\hline $\mathrm{M} 4^{4}$ & Enclosure & 2.5 \\
\hline M5 & Enclosure & 3.5 \\
\hline M6 & Enclosure & 2.5 \\
\hline
\end{tabular}

${ }^{1} \mathrm{~F}$, female; $\mathrm{M}$, male

${ }^{2} \mathrm{Had}$ kid during first year post release

${ }^{3}$ Died 11 weeks post release

${ }^{4}$ Died 10 weeks post release

inter-fix distance (i.e. the linear distance between successive fixes), as a measure of their mobility (i.e. dispersal behaviour in the new site); (2) maximum distance from the release site; and (3) overlap of successive weekly home ranges (minimum convex polygon).

\section{Results}

Two males (aged 7.5 and 2.5 years) died during the first 20 weeks after release (Table 1). The last radiolocation for both individuals was far from the release site (M3: $8.4 \mathrm{~km}$; M4: 8.9 $\mathrm{km})$, apparently indicating dispersal.

Individuals caught in the wild moved (inter-fix distance) significantly more than those from captivity during the first few weeks after release (Mann-Whitney $U$ Test; week 1: $U=5.0, \mathrm{P}=0.029, N_{\mathrm{w}}=5, N_{\mathrm{e}}=8$; week $2: U=6.0$, $\mathrm{P}=0.045, N_{\mathrm{w}}=5, N_{\mathrm{e}}=8$; week 4: $U=5.0, \mathrm{P}=0.003$, $N_{\mathrm{w}}=8, N_{\mathrm{e}}=8$; week 19: $U=3.0, \mathrm{P}=0.004, N_{\mathrm{w}}=7$, $N_{\mathrm{e}}=7$; Fig. 2a). Males moved significantly more than females (Mann-Whitney $U$ Test; week 6: $U=7.0, \mathrm{P}=0.011$, $N_{\mathrm{f}}=10, N_{\mathrm{m}}=6$; week $7: U=7.0, \mathrm{P}=0.011, N_{\mathrm{f}}=10$, $N_{\mathrm{m}}=6$; week 10: $U=3.0, \mathrm{P}=0.002, N_{\mathrm{f}}=10, N_{\mathrm{m}}=6$; week 14: $U=4.0, \mathrm{P}=0.024, N_{\mathrm{f}}=10, N_{\mathrm{m}}=4$ ). There were no significant differences between young (females $<3$ years, males $<4$ years) and adults (females $\geq 3$ years, males $\geq 4$ years; Mann-Whitney $U$ Test; $U=14.0-29.0$, $\left.\mathrm{P}=0.093-1.000, N_{\mathrm{a}}=7-9, N_{\mathrm{y}}=6-7\right)$.

Wild-caught individuals moved significantly further from the release site than those from captivity only during the first week after release (Mann-Whitney $U$ Test; week 1: $U=3.0, \quad \mathrm{P}=0.011, \quad N_{\mathrm{w}}=5, \quad N_{\mathrm{e}}=8 ;$ other weeks: $\quad U=14.0-31.0, \quad \mathrm{P}=0.209-1.000, \quad N_{\mathrm{w}}=5-8$, $N_{\mathrm{e}}=7-8$ ), with a high variability during the first 11 weeks (Fig. 2b). No significant differences were found between sexes (Mann-Whitney $U$ Test; $U=11.0-26.0, \mathrm{P}=0.093^{-}$ 1.000, $\left.N_{\mathrm{f}}=8-10, N_{\mathrm{m}}=4-6\right)$ or between young and adult animals (Mann-Whitney $U$ Test; $U=10.0-28.0$, $\left.\mathrm{P}=0.093-0.958, N_{\mathrm{a}}=7-9, N_{\mathrm{y}}=5-7\right)$.

We calculated the percentage of overlap between individual home ranges in successive weeks: individuals caught in the wild shifted their home ranges significantly more than those from captivity (Mann-Whitney $U$ Test; week 1-2: $U=4.0, \mathrm{P}=0.048, N_{\mathrm{w}}=4, N_{\mathrm{e}}=8$; week 10-11: $U=8.0, \mathrm{P}=0.037, N_{\mathrm{w}}=7, N_{\mathrm{e}}=7$; other weeks: $U=8.0-$ 31.0, $\left.\mathrm{P}=0.073^{-0.959,} N_{\mathrm{w}}=4-8, N_{\mathrm{e}}=7-8\right)$. No significant differences were found between sexes (Mann-Whitney $U$ Test; $U=11.0-25.0, \quad \mathrm{P}=0.260-0.945, \quad N_{\mathrm{f}}=7-10$, $N_{\mathrm{m}}=4-6$ ) or between young and adult animals (MannWhitney $U$ Test; $U=14.0-28.0, \mathrm{P}=0.190-1.000, N_{\mathrm{a}}=6-9$, $N_{\mathrm{y}}=5-7$ ).

Seven of the 10 females had one kid in the first year after release (Table 1). Of the three females with no kid, two were from the wild and one was from captivity.

\section{Discussion}

A conservation introduction aims to preserve a threatened species in an area outside its historical distribution but within an appropriate habitat and eco-geographical area. Reintroduced/introduced populations are small initially and therefore susceptible to the risks faced by all small populations (e.g. environmental fluctuations, demographic stochasticity and inbreeding; Caughley \& Sinclair, 1994). To achieve success a primary aim of introductions or reintroductions should be to maximize the initial rate of population increase and thereby shorten the period during which the new population is exposed to risks. In a review Komers \& Curman (2000) showed that a significant proportion of variation in the rate of increase of reintroduced Artiodactyla populations is explained by age and sex structure. In particular, the proportion of socially mature animals is positively correlated to population growth, as is the proportion of males to females (Komers \& Curman, 2000). In our study, post-release mortality affected only males, probably on dispersal, and was independent of age or origin. Captive-bred females showed greater reproductive success (and hence higher recruitment) compared to those wild-caught, which may be attributable to better body condition. However, this is a preliminary finding; in reintroduction programmes reproductive success usually improves significantly with time after release (Saltz \& Rubenstein, 1995; Jiang et al., 2000; Bar-David et al., 2005).

Nutrition during early development has been shown to have an effect on reproductive physiology and behaviour in adulthood (Curio, 1996), and therefore food availability and 

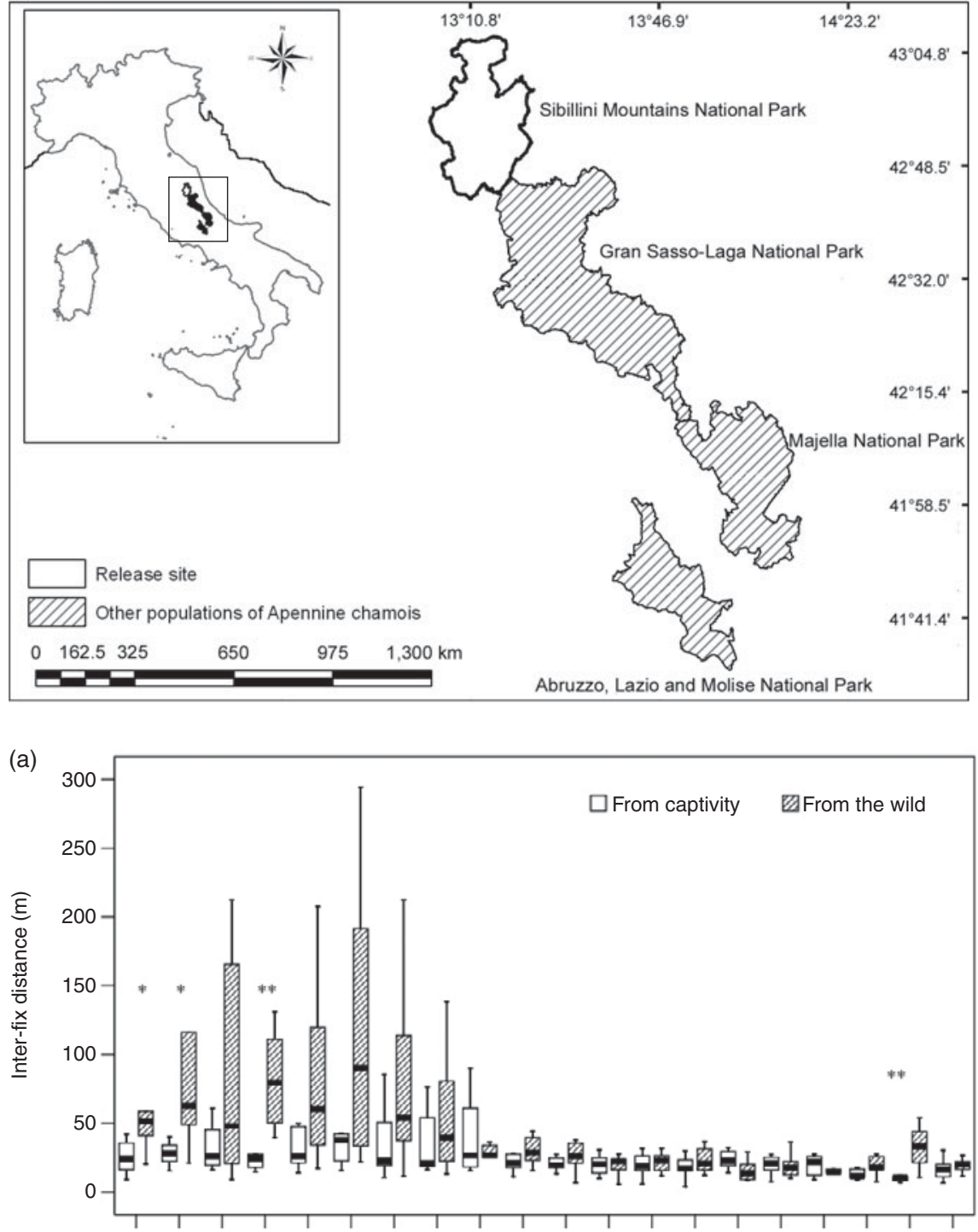

(b)

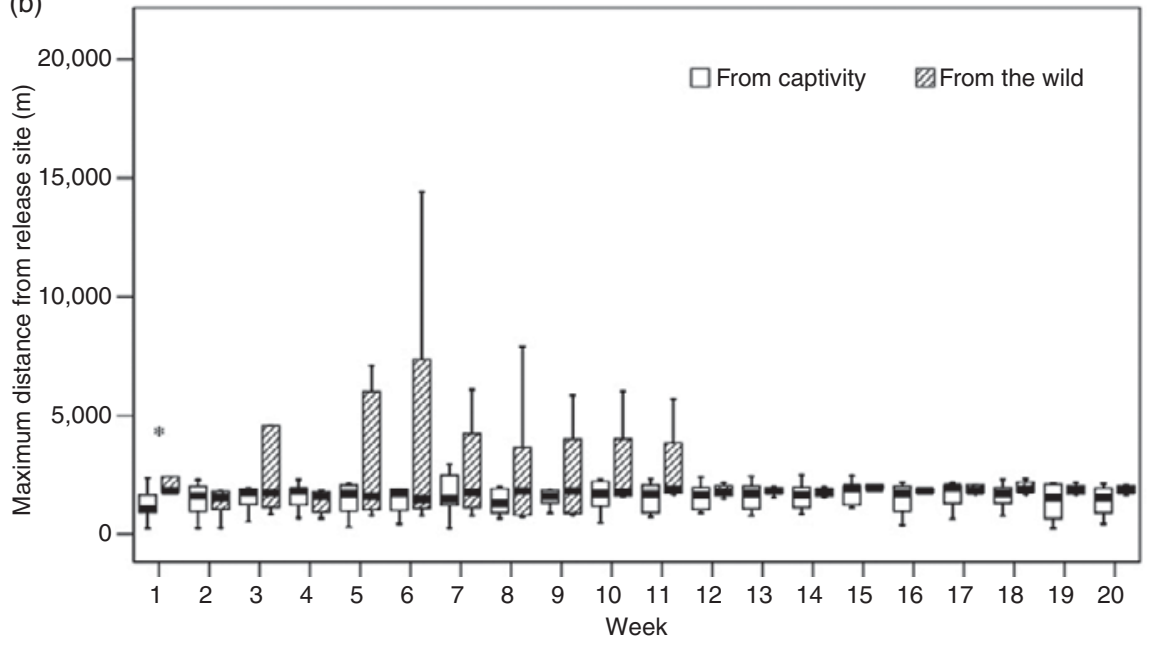

FIg. 1 Sibillini Mountains National Park, Italy, where 16 Apennine chamois Rupicapra pyrenaica ornata were released during 2008-2010. Other populations of the species exist in the Abruzzo, Lazio and Molise National Park, Majella National Park and the Gran Sasso-Monti Laga National Park. The rectangle on the inset indicates the location of the main map in Italy. Coordinates are in WGS84 system.
FIG. 2 (a) Inter-fix distance (median values and quartiles) moved, and (b) maximum distance moved from the release site, by 16 captive-bred and wild-caught Apennine chamois (Table 1) during the first 20 weeks following their release in the Sibillini Mountains National Park (Fig. 1). ${ }^{*} \mathrm{P}<0.05,{ }^{* *} \mathrm{P}<0.01$, MannWhitney $U$ test. parental feeding are important for both wild and captive stock.

The age and sex structure of an introduced/reintroduced population influences its success because it determines the spatial behaviour of founders. The first few weeks after release are a period of spatial instability, with animals behaving unpredictably (Kleiman, 1989). Usually, young individuals exhibit greater dispersion after release than 
adults (Greenwood, 1980; Calenge et al., 2005), and males disperse more than females (Moseby \& O'Donnell, 2003; Lovari et al., 2010). Analysing the spatial behaviour of our introduced individuals during the first 20 weeks after release we found no significant differences between males and females or between young animals and adults. There were significant differences between captive-bred and wildcaught founders, the former showing greater site fidelity. This is a particularly important issue in introductions/ reintroductions because it is desirable that individuals remain near each other and close to the release site (i.e. the most suitable area for the new population) rather than dispersing immediately after release. A large post-release dispersion rate may reduce the potential to establish a breeding population (Hardman \& Moro, 2006). This is even more important when founders are released just before the mating season (as in this study) because they may miss mating opportunities.

Griffith et al. (1989) showed how translocations of exclusively wild-caught animals were more likely to succeed than those of exclusively captive-reared animals. In a review Beck et al. (1994) found that wild populations were established successfully in only $11 \%$ of reintroductions of captivebred animals. The causes of failure are mainly associated with behavioural deficiencies in captive-bred animals, especially in relation to foraging, predator avoidance and social behaviour (Beck et al., 1994). We used a mixed strategy, with wild and captive-bred animals, because the source wild population could not provide enough animals. This appears to be a good compromise, maintaining the animals close to the release area and at the same time increasing genetic variability and reducing risks linked to ignorance of local ecological features. We suggest that this mixed strategy may improve the success of releases for species that are not abundant in the wild.

\section{Acknowledgements}

We are greatly indebted to A. Rossetti, F. Mari, N. Felicetti, and the staff of Abruzzo, Lazio and Molise National Park, Majella National Park and Gran Sasso-Monti Laga National Park for their help in the field. A. Fermanelli and F. Perco provided support throughout our work. Two anonymous reviewers provided helpful comments. SL received financial support from the Sibillini Mountains National Park Agency and, from 2010, through the LIFEo9 NAT/IT/0oo183 COORNATA. The Italian Army and the Corpo Forestale dello Stato facilitated the transportation of the animals to the Sibillini Mountains National Park.

\section{References}

Apollonio, M., Bassano, B. \& Mustoni, A. (2003) Behavioural aspects of conservation and management of European mammals. In
Animal Behavior and Wildlife Conservation (eds M. Festa-Bianchet \& M. Apollonio), pp. 157-170. Island Press, Washington, DC, USA.

Banks, P.B., Norrdahl, K. \& Korpimäki, E. (2002) Mobility decisions and the predation risks of reintroduction. Biological Conservation, 103, 133-138.

Bar-David, S., Saltz, D., Dayan, T., Perelberg, A. \& Dolev, A. (2005) Demographic models and reality in reintroductions: Persian fallow deer in Israel. Conservation Biology, 19, 131-138.

Beck, B.B., Rapaport, L.G., Stanley Price, M.R. \& Wilson, A.C. (1994) Reintroduction of captive-born animals. In Creative Conservation: Interactive Management of Wild and Captive Animals (eds P.J.S. Olney, G.M. Mace \& A.T.C. Feistner), pp. 265-286. Chapman \& Hall, London, UK.

Berger, J. (1990) Persistence of different-sized populations: an empirical assessment of rapid extinctions in bighorn sheep. Conservation Biology, 4, 91-98.

Bertolino, S. (2003) Herd defensive behaviour of chamois, Rupicapra rupicapra, in response to predation on the young by a golden eagle, Aquila chrysaetos. Zeitschrift für Jagdwissenschaft, 49, 233-236.

Bright, P.W. \& Morris, P.A. (1994) Animal translocation for conservation: performance of dormice in relation to release methods, origin and season. Journal of Applied Ecology, $31,699-708$.

Bronson, F.H. (1989) Mammalian Reproductive Biology. The University of Chicago Press, Chicago, USA.

Burgman, M.A. \& Lindenmayer, D.B. (1998) Conservation Biology for the Australian Environment. Surrey Beatty and Sons, Chipping Norton, Australia.

Calenge, C., Maillard, D., Invernia, N. \& Gaudin, J.-C. (2005) Reintroduction of roe deer Capreolus capreolus into a Mediterranean habitat: female mortality and dispersion. Wildlife Biology, 11, 153-161.

Caughley, G. (1994) Directions in conservation biology. Journal of Animal Ecology, 63, 215-244.

Caughley, G. \& Sinclair, A.R.E. (1994) Wildlife Ecology and Management. Blackwell Scientific Publications, Boston, USA.

Clark, J.D., Huber, D. \& Servheen, C. (2002) Bear reintroductions: lessons and challenges. Ursus, 13, 335-345.

Couturier, M. (1938) Le chamois. Arthaud, Grenoble, France.

Cunningham, A.A. (1996) Disease risks of wildlife translocations. Conservation Biology, 10, 349-353.

Curio, E. (1996) Conservation needs ethology. Trends in Ecology \& Evolution, 11, 260-263.

Dolev, A., Saltz, D., Bar-David, S. \& Yom-Tov, Y. (2002) Impact of repeated releases on space-use patterns of Persian fallow deer. The Journal of Wildlife Management, 66, 737-746.

Festa-Bianchet, M. (2002) Landscape-level movements of mountain ungulates: carrying genes and pathogens between populations. Mountain Science Highlights, 1, 13-14.

Fischer, J. \& Lindenmayer, D.B. (2000) An assessment of the published results of animal relocations. Biological Conservation, $96,1-11$.

GinsberG, J.R. (1994) Captive breeding, reintroduction and the conservation of canids. In Creative Conservation: Interactive Management of Wild and Captive Animals (eds P.J.S. Olney, G.M. Mace \& A.T.C. Feistner), pp. 365-383. Chapman \& Hall, London, UK

Gogan, P.J.P. \& BARRetT, R.H. (1987) Comparative dynamics of introduced mule elk populations. The Journal of Wildlife Management, 51, 20-27.

Greenwood, P.J. (1980) Mating systems, philopatry and dispersal in birds and mammals. Animal Behaviour, 28, 1140-1162. 
Griffith, B., Scott, M.J., Carpenter, J.W. \& Reed, C. (1989) Translocation as a species conservation tool: status and strategy. Science, 245, 477-480.

Hardman, B. \& Moro, D. (2006) Optimising reintroduction success by delayed dispersal: is the release protocol important for hare-wallabies? Biological Conservation, 128, 403-411.

Hooge, P.N. \& Eichenlaub, B. (1997) Animal Movement Extension to ArcView. Alaska Science Center, Biological Science Office, U.S. Geological Survey, Anchorage, USA.

IUCN (2012) Guidelines for Reintroductions and Other Conservation Translocations v. 1.o. IUCN Species Survival Commission, Gland, Switzerland.

Jiang, Z., Yu, C., Feng, Z., Zhang, L., Xia, J., Ding, Y. \& LiNDSAY, N. (2000) Reintroduction and recovery of Père David's deer in China. Wildlife Society Bulletin, 28, 681-687.

Jule, K.R., Leaver, L.A. \& Lea, S.E.G. (2008) The effects of captive experience on reintroduction survival in carnivores: a review and analysis. Biological Conservation, 141, 355-363.

Kleiman, D.G. (1989) Reintroduction of captive mammals for conservation. Guidelines for reintroducing endangered species into the wild. BioScience, 39, 152-161.

Komers, P.E. \& Curman, G.P. (2000) The effect of demographic characteristics on the success of ungulate re-introductions. Biological Conservation, 93, 187-193.

Lovari, S., Artese, C., Damiani, G. \& Mari, F. (2010) Reintroductions of Apennine chamois to the Gran Sasso-Laga National Park, Italy. In Global Re-introduction Perspectives: Additional Case-studies from Around the Globe (ed. P.S. Soorae), p. 352. IUCN/SSC Re-introduction Specialist Group, Abu Dhabi, UAE.

Mari, F. \& Lovari, S. (2006) The release of Apennine chamois in Central Italy: 20 years later. Reintroduction News, 25, 21-22.

Masini, F. \& Lova RI, S. (1988) Systematics, phylogenetic relationships and dispersal of the chamois (Rupicapra spp.). Quaternary Research, 30, 339-349.

Mathews, F., Moro, D., Strachan, R., Gelling, M. \& Buller, N. (2006) Health surveillance in wildlife reintroductions. Biological Conservation, 131, 338-347.

Michallet, J. \& Tol̈go, C. (2000) Home ranges of chamois (Rupicapra rupicapra cartusiana) translocated to reinforce a population in the Grande Chartreuse mountain massif, Isère. Game \& Wildlife Science, 17, 259-272.

Moseby, K.E. \& O'Donnell, E. (2003) Reintroduction of the greater bilby, Macrotis lagotis (Reid) (Marsupialia: Thylacomydae), to northern South Australia: survival, ecology and notes on reintroduction protocols. Wildlife Research, 30, 15-27.

Owen-Smith, N. (2003) Foraging behavior, habitat suitability, and translocation success, with special reference to large mammalian herbivores. In Animal Behaviour and Wildlife Conservation (eds M. Festa-Bianchet \& M. Apollonio), pp. 93-109. Island Press, Washington, DC, USA.

SAlTZ, D. (1998) A long-term systematic approach to planning reintroductions: the Persian fallow deer and the Arabian oryx in Israel. Animal Conservation, 1, 245-252.

Saltz, D. \& Rubenstein, D.I. (1995) Population dynamics of a reintroduced Asiatic wild ass (Equus hemionus) herd. Ecological Applications, 5, 327-335.

Sarrazin, F. \& Barbault, R. (1996) Reintroduction: challenges and lessons for basic ecology. Trends in Ecology \& Evolution, 11, $474-478$.

Sarrazin, F. \& Legendre, S. (2000) Demographic approach to releasing adults versus young in reintroductions. Conservation Biology, 14, 488-500.

SigG, D.P., Goldizen, A.W. \& Pople, A.R. (2005) The importance of mating system in translocation programs: reproductive success of released male bridled nailtail wallabies. Biological Conservation, 123, 289-300.

Springer, J.T. (1979) Some sources of bias and sampling error in radio triangulation. The Journal of Wildlife Management, 43, 926-935.

Stanley Price, M.R. (1989) Animal Re-introductions: the Arabian Oryx in Oman. Cambridge University Press, Cambridge, UK.

Vickery, S.S. \& MASON, G.J. (2003) Behavioral persistence in captive bears: implications for reintroduction. Ursus, 14, 35-43.

Wolf, C.M., Garland, JR, T. \& Griffith, B. (1998) Predictors of avian and mammalian translocation success: reanalysis with phylogenetically independent contrasts. Biological Conservation, 86, 243-255.

WWF (1997) Studio di fattibilità per la reintroduzione del Camoscio d'Abruzzo (Rupicapra pyrenaica ornata) nel Parco Nazionale dei Monti Sibillini e nel Parco Regionale Sirente Velino. Technical report. WWF Italia, Rome, Italy.

\section{Biographical sketches}

A. Bocci's research activities include wildlife monitoring and management, spatial behaviour and habitat selection. She has experience in capturing and marking wildlife, census techniques, radiotelemetry, diet analysis of carnivores, and GIS applications. S. Menapace and S. Alemanno are wildlife technicians at the Sibillini Mountains National Park, where they have participated in radiotracking of Apennine chamois since 2009. S. LOVARI has been working steadily on the biology of chamois since 1976 and was chairman of the IUCN Caprinae Specialist Group from 1986 to 1998. 